\title{
Effects of Long-Term Flow Variation on Microhydropower Energy Production in Pressure Reducing Valves in Water Distribution Networks
} Brady, Jennifer; Gallagher, John; Corcoran, Lucy; Coughlan, Paul; McNabola, Aonghus

\section{Journal of Water Resources Planning and Management}

\section{DOI:}

10.1061/(ASCE)WR.1943-5452.0000731\#sthash.PsUSgcdr.dpuf

Published: 01/03/2017

Peer reviewed version

Cyswllt i'r cyhoeddiad / Link to publication

Dyfyniad o'r fersiwn a gyhoeddwyd / Citation for published version (APA):

Brady, J., Gallagher, J., Corcoran, L., Coughlan, P., \& McNabola, A. (2017). Effects of LongTerm Flow Variation on Microhydropower Energy Production in Pressure Reducing Valves in Water Distribution Networks. Journal of Water Resources Planning and Management, 143(3). https://doi.org/10.1061/(ASCE)WR.1943-5452.0000731\#sthash.PsUSgcdr.dpuf

\footnotetext{
Hawliau Cyffredinol / General rights

Copyright and moral rights for the publications made accessible in the public portal are retained by the authors and/or other copyright owners and it is a condition of accessing publications that users recognise and abide by the legal requirements associated with these rights. study or research

- Users may download and print one copy of any publication from the public portal for the purpose of private

- You may not further distribute the material or use it for any profit-making activity or commercial gain

- You may freely distribute the URL identifying the publication in the public portal?
}

Take down policy

If you believe that this document breaches copyright please contact us providing details, and we will remove access to the work immediately and investigate your claim. 
1 Effects of Long-term Flow Variation on Micro-Hydropower Energy Production in Pressure

2 Reducing Valves in Water Distribution Networks.

3 Jennifer Brady ${ }^{1}$, John Gallagher ${ }^{2}$, Lucy Corcoran ${ }^{3}$, Paul Coughlan ${ }^{4}$ Aonghus McNabola ${ }^{5}$

4

5 ABSTRACT

6 Incorporating micro-hydropower (MHP) turbines within water supply networks has the potential to

7 improve the economic and environmental sustainability of the sector. However, long-term flow and head

8 variations in water networks is a key risk factor which increases turbine performance uncertainty in the

9 medium-to-long term, potentially impacting on the investment payback period. Using high-resolution

10 historical flow and head data across a number of pressure reducing valve sites in water networks in

11 Ireland, this study presents an assessment of the impact of flow and head variations on turbine efficiency

12 and power output over a twenty year period. Results indicated that pumps-as-turbines (PATs) represent

13 a viable low-cost option over the long-term, at sites with smaller power output potential. Where flow

14 and head rates displayed considerable fluctuation, the integration of a two-PAT configuration could 
15 improve operating efficiency and maximise power output. This design strategy opens up the opportunity 16 to conduct energy recovery from sites which may previously have been considered unsuitable for MHP.

\section{Keywords}

Water Supply; Micro-hydropower; Energy recovery; Pressure reducing valve; Pump-as-turbine

\section{Introduction}

22 A continuous high quality water supply is a vital facet of effective societal and economic development

23 across nations. Such continuity of service is predicated on sustained energy security and affordability

24 into the future. The water industry is particularly vulnerable within this context as water abstraction, 25 treatment and distribution are energy intensive processes. Globally, 2-3\% of total energy consumption is associated with pumping and treating water (Kwok et al. 2010). The UK water industry for example,

27 utilises approximately 3\% of total energy demand (Environment Agency, 2009) emitting over 5 million

28 tonnes of $\mathrm{CO}_{2}$ emissions annually (DEFRA, 2008). Concurrently, the overall cost of water provision is

29 rising due to increased energy costs (Zilberman et al. 2008). In Ireland, water service provision costs 30 have been increasing by approximately 7.5\% per year since 2007 and key drivers include higher capital 31 investment requirements, rising energy costs together with more stringent regulatory compliance in 32 terms of both national and European Union (EU) legislation (DoEHLG, 2010). Accordingly, there is a 33 pressing need to achieve greater efficiencies across water infrastructure in conjunction with the 34 integration of economically viable renewable energy technology solutions.

35 Opportunities exist for energy efficiencies across the entire water supply chain. A breakdown of 36 energy demand across water service provision reveals that water distribution accounts for $45 \%$ of total 37 energy consumption (Daigger, 2009). Many water utilities are now incorporating renewable 
diversification with a range of energy applications including: hydropower, wind turbines, solar power, the generation of energy in wastewater treatment facilities (Kwok et al. 2010; UKWIR 2010).

In terms of hydropower, large-scale installations are widespread on a global scale, yet, microhydropower (MHP) at various water infrastructure locations has experienced limited market penetration to date (Gaius-obaseki 2010). Vilanova and Balestieri (2014) note that the use of hydraulic turbines inserted within water distribution networks represents one of the most complex forms of energy recovery in water supply systems. There is a need to address identified barriers to the uptake of MHP in an effort to strengthen the investment case for greater acceptance of this technology in the water industry (McNabola et al., 2014a). One such barrier is long-term network flow and head variation and their potential impact on the operational efficiency of turbines.

Turbines are designed for a relatively stable flow rate, yet flow variation can occur diurnally, seasonally and over the long-term which can impact on efficiency and thus capital payback (Sitzenfrei and Rauch, 2015). Carravetta et al. (2014a) highlight the importance of flexibility within an energy production system given that operating conditions can vary due to network flow variation during its life cycle. Climate change, population growth, leakage rates, water pricing and economic activity have all been shown to have an impact on long-term flow and head variations in water distribution networks (Corcoran et al., 2016).

Considering the initial high capital investment requirement, there is a need to ensure the long-term viability of a MHP installation. Accordingly, this paper aims to investigate long-term fluctuations in flow rates and head over time at three potential hydropower locations within the water supply network of Dublin City (Ireland). The viability and operational resilience of three turbine options including a Kaplan and pumps-as-turbines (PATs) are assessed and outcomes are compared in terms of energy recoverable, payback periods and gross income. The paper concludes with engineering design recommendations regarding future MHP installations in light of potential increases in flow/head variability into the future. 


\section{Hydropower Energy Recovery in Water Networks}

The potential for energy recovery via MHP has been identified within water supply networks at points of high flow or surplus hydraulic head which otherwise needs to be dissipated for pressure management purposes (Vicente et al. 2016). Such applications include flow control valves, pressure reducing valves (PRVs), storage/service reservoirs, break pressure tanks and wastewater treatment plants (Williams et al. 1998; Saket 2008; Gaius-obaseki 2010; Corcoran et al. 2012; Power et al. 2014; McNabola et al. 2014a; Samora et al. 2016). This excess energy can be recovered and converted into electricity without reducing the level of service to customers.

Specifically, pressure reducing valves (PRVs) have been identified as a large untapped resource and Carravetta et al. (2014b) note that the number of PRVs is increasing across networks as they can reduce leakage and delay the need for expensive rehabilitation works. Gaius-obaseki (2010) states that up to $85 \%$ of wasted energy can be recovered through replacement of a PRV with a turbine or alternatively through installing a turbine and a PRV in parallel. However, technological and economic viability barriers exist which to date have prevented the exploitation of this potential energy saving.

Many studies have identified the potential for pumps-as-turbines (PATs) to produce energy in water networks (Williams 1996; Ramos and Borga 1999; García et al. 2010; Carravetta et al. 2012; Carravetta et al. 2014b; Fecarotta et al. 2015). PATs, where a water pump is run in reverse, have a cost advantage over conventional turbines for small scale energy generation, as a wide range of pump sizes are mass produced. Furthermore, they are easy to install (Williams 1996) and spare parts are widely available (Agarwal 2012). In contrast, hydraulic turbines are considerably more expensive due to fact that they are specifically designed for each site. However, they display greater efficiencies over a wider range of flow and head rates when compared to PATs. Additionally, PATs do not possess a regulation device so this must be included during installation where pressure control is required (Carravetta et al. 2014a). To date, real scale installation of hydraulic turbines and PATs within water distribution networks remains somewhat limited. There are evident challenges when installing either turbine option within the small 
distribution network setting, specifically the smaller power potential across sites and high variability in hydraulic characteristics when compared to larger transmission pipelines (Giugni et al. 2014; Carravetta et al. 2014b). Furthermore, previous research has established that a mere 10\% change in flow rate at a small sized plant can increase the payback period and render a MHP project unsuitable (McNabola et al. 2014b).

Given that MHP installations typically have an investment payback period of 10 years, there is a need to assess future flow uncertainties into the medium-to-long term. Research regarding the impact of demand uncertainty and long-term flow variation specifically on turbine efficiency is relatively limited. Sitzenfrei and von Leon (2014) utilised ten years of hourly water consumption data in a simulation model for the design and optimisation of a small hydropower system testing various turbine sizes. Additional research involved the use of this long-time simulation model to analyse the effects on a small hydropower system in which a control mechanism for the device was optimised in order to maximise profits (Sitzenfrei et al. 2014). More recently, Sitzenfrei and Rauch (2015) assessed the impact of different future population and demand scenarios on the performance of a small Pelton hydropower system in Austria and the authors stressed that disregarding both long-term demand patterns and demand uncertainty hinders the attainment of a realistic evaluation of potential profits. Similarly, Colombo and Kleiner (2011) highlight the importance of considering changes in demand over time. Their study probabilistically analysed the feasibility of energy recovery via micro turbines and identified that diurnal and seasonal demand fluctuations can significantly impact project return.

The optimal choice of turbine is dictated by the flow and pressure range of the site (Gaius-obaseki, 2010) and high variability in user demand can significantly impact turbine suitability. Sitzenfrei et al. (2014) comment that within a 20-year period, water infrastructure and small hydropower installations can be significantly impacted by population dynamics and water use. Limited research has analysed the performance and operational efficiency of turbines using historical long-term flow data, and no investigations have examined the long-term performance of PATs to date. Accordingly, this study aims 
113 to fill this gap through assessment of historical flow and head variation using up to twenty years of high114 resolution data across three PRV sites within a water distribution network and analysing the resulting 115 impact on available volumes of water for energy production across a number of different turbine design 116 scenarios. A near-optimal MHP design strategy for small capacity sites, in terms of improving turbine 117 efficiency performance over the long-term, is subsequently developed and discussed.

\section{Methodology}

\subsection{Simulation of long-term turbine performance}

122 The study firstly analyses the extent of long-term fluctuations in flow and head across three PRV sites 123 over a period of up to 20 years. It was anticipated that due to population and economic growth, user 124 demand and thus flow rates would change significantly over the time period across the three sites.

125 The first year of data in each historical record was utilised to establish a design flow for a 126 hypothetical turbine installation at each location, assuming year one in the historical dataset represented 127 the present day. It is common practice in the design of MHP installations in both run-of-river and water 128 network settings to establish the turbine design flow, $\mathrm{Q}_{0}$, based on the average flow from one year of 129 flow data. However as this paper aims to demonstrate, such practices are fraught with inaccuracies, most 130 particularly in water distribution.

The paper presents a theoretical simulation of the potential performance of varying turbine design options at the three PRV sites over the intervening years in the historical record (16-19 years), assuming that these data represent future flow rates. Turbine efficiencies were evaluated over this long-term period in response to flow and head variation. Total reductions in $\mathrm{CO}_{2}$ emissions were also estimated. 
137 The three turbine design scenarios investigated are displayed in Figure 1. Firstly, a traditional Kaplan 138 turbine was selected due to its wide high-efficiency range (see Figure 3) and suitability for the low-head 139 and high-flow conditions of the three PRVs. Secondly, a single PAT was assessed at each site. Whilst a 140 PAT possesses a narrower high-efficiency range, it is considerably lower in cost when compared to a 141 conventional hydraulic turbine. year 1 or alternatively through the smaller sized PAT designed for $50 \%$ less than that design flow. Therefore, the optimal choice of PAT in scenario three was dependent on the incoming flow rate and flow was switched to the smaller PAT when this would produce a higher power output. This two-PAT scenario was included in order to increase efficiency and power generation potential. Both PAT systems also included the concept of a hydraulic regulation device to control downstream pressure as described by Carravetta et al. (2014a). All turbine scenarios incorporated a by-pass system to prevent disruption to the supply service in the event of maintenance requirements or failure of the turbine.

\subsection{Case Study Area - Dublin}

156 This study builds on previous research regarding the MHP energy recovery potential of the Dublin water 157 supply network (Corcoran et al. 2012, 2013, 2016; McNabola et al. 2014b) through analysis of a subset 
comprising either a hydraulic turbine or a PAT is investigated with the aim of exploring their operational efficiencies and economic suitability over the long-term.

Figure 2. Map of the Dublin region displaying the location of the three pressure reducing valves used in the case study.

High resolution telemetry data of flow and head at 15 minute intervals collected by Dublin City Council was utilised for simulation of turbine performance across three PRV sites: Thomas Court; Blackhorse Bridge; and Merrion Gates, over 20 years (up to 700,800 measurements). These sites were selected as they possessed different flow and head characteristics together with varied power output potential, as outlined in Table 1. Head data comprised both inlet and outlet head readings. The availability of data varied across sites ranging from 17 years up to 20 years (1993 to 2013).

Thomas Court was located on a section of the network which feed a large industrial user of water. This user was the largest water user in Dublin and required a high flow rate. High flow and pressure was delivered to this location to meet processing needs. The Blackhorse bridge PRV was located in a mainly residential area, while Merrion Gates was located adjacent to a large hospital. Each site served quite differing water demand types, which partly explains the reasons for differing head and flow values shown in Figure 4. In addition to this, each of the 3 values are located in differing sections of Dublin, one in the city centre, one in the south and one in the north-west. The cumulative demands from source to supply in each area was different.

\subsection{Simulation of Power Output Potential and Estimation of Return of Investment}


The three sites differed regarding their estimated power potential. Table 1 displays the average flow rate, head and estimated power potential across the PRVs.

Table 1. An overview of flow, head and power output estimates for three PRVs in Dublin. Power estimates were based on varying Kaplan turbine efficiencies, where the turbine design flow/head was assumed to be the average of the data from year 1 of the record.

The potential power output at each site was simulated for every 15 minute interval within the 20-year dataset using equation (1), where $P$ represents the power output $(\mathrm{kW}), Q$ is the flow rate through the turbine $\left(\mathrm{m}^{3} / \mathrm{s}\right), \rho$ is fluid density $\left(\mathrm{kg} / \mathrm{m}^{3}\right), g$ is acceleration due to gravity, $H$ is the available head (PRV head drop) at the turbine $(\mathrm{m})$ and $e_{o}$ represents the overall system efficiency.

$$
P=Q \rho g H e_{o}
$$

Therefore flow and head varied according to their measured input values (head was taken as the difference between input and output head at the PRV i.e. available excess head). Overall system efficiency included a variable turbine efficiency value together with generator and transmission loss efficiencies estimated to be $85 \%$ and $98 \%$ respectively (Power et al., 2014). Turbine rotational speed and therefore efficiency varied according to the extent of deviations in the instantaneous flow and head measurements from their design values (selected as the average flow and average head in year 1 of the data records). Turbine efficiency curves, adapted from Corcoran et al. (2013) and Ørke (2010), were used to quantify these changes as shown in Figure 3. A sixth-degree polynomial equation was fitted to data in each efficiency curve and used to estimate of overall system efficiencies for each turbine option according to Equation 2. In terms of historical demands and turbine design, the average flow rate over the first year of available data at each PRV site was utilised as the design flow criteria for each turbine 
203 option. For the two-PAT scenario, the design flow for the second smaller PAT was chosen as 50\% less 204 than the average annual flow rate.

205

206

207

208

209

210

211

212
Figure 3. Overall system efficiency curves for the Kaplan turbine and PAT, assuming generator and transmission loss efficiencies of $85 \%$ and $98 \%$ respectively.

$$
e_{0}=e_{\text {turbine }} \times e_{\text {generator }} \times e_{\text {transmissin }}
$$

Where $e_{\text {turbine }}$ is the instantaneous turbine efficiency; $e_{\text {generator }}$ is the generator efficiency; and $e_{\text {transmission }}$ is the transmission efficiency.

In terms of assessing economic feasibility, a payback period approach was applied where the payback period equals the investment cost divided by the net annual revenue (ESHA, 2004). In general, MHP projects which exceed a payback period of 10 years are not considered viable by water utilities (McNabola et al., 2014b). The overall costs of an MHP installation comprise the initial installation costs (design, construction, installation and commissioning) and subsequent operation and maintenance costs. Generally, MHP projects require large upfront investment costs with low recurring costs thereafter. Installation costs for an MHP turbine are mainly site specific and can differ depending on the amount of civil works needed and proximity to the grid. It has been estimated that capital costs for the installation of micro-hydropower are in the range of $£ 3,000$ to $£ 6,000$ per $\mathrm{kW}$ installed and costs decrease with an increase in capacity or for higher head turbines (Gaius-obaseki, 2010). Similarly, MHP turbine installation costs in America are estimated to be in the region of $\$ 3,500-\$ 7,000 / \mathrm{kW}$ whilst maintenance costs are approximately $\$ 2,000$ annually (Colombo and Kleiner, 2011). In the present study, installation costs for the Kaplan turbine were estimated using an empirical formula developed by Ogayar et al. (2009) based on power output and hydraulic head (Equation 3). The cost per $\mathrm{kW}$ for a PAT was 
226 estimated at $€ 350 / \mathrm{kW}$ according to previous research undertaken by Carravetta et al. (2013), as no cost227 power-head function is currently available for PATs.

$$
\text { Kaplan Cost }=31196 . P^{0.41662} \cdot H^{-0.113901}
$$

230 Where Kaplan cost represents the euro value of electromechanical equipment; $P$ is the power output $231(\mathrm{~kW})$; and $H$ is the head $(\mathrm{m})$. Both of these costs estimates relate to the electromechanical equipment 232 only and do not incorporate civil construction works. In the present study it was assumed that the turbine cost represented $30 \%$ of total installation costs, signalling that civil and construction works amounted to $23470 \%$ of total expenditure, as per previous research findings (Gallagher et al. 2015). An additional fixed 235 maintenance costs of $€ 1,496(\$ 2,000)$ per annum (Colombo and Kleiner 2011) was also incorporated in 236 the economic analysis.

It was assumed that the electricity generated would be utilised on site rather than connecting to the grid, thus reducing the total investment requirement. This option has previously been found to be more economically advantageous in Ireland due to low REFIT rates for MHP (Corcoran et al. 2013). 240 Accordingly, annual power generation was multiplied by the end user industrial price of electricity for 2412013 of $€ 0.137 / \mathrm{kW}$, in order to establish annual electricity savings (Eurostat 2014b). In terms of the 242 environmental benefit, equivalent $\mathrm{CO}_{2}$ emissions from electricity generation were calculated based on 2432013 figures of $528 \mathrm{~g}$ per $\mathrm{kWh}$ in Ireland (SEAI, 2013).

2454 Analysis and Results 
247 Average annual flow and head data for each PRV site are displayed in Figure 4. The analysis revealed 248 considerable variability between sites and highlights the influence of local water demands in each area. 249 The Merrion Gates PRV, for example, served a nearby hospital which would possess a different demand 250 pattern when compared to flow feeding residential or commercial districts. Whilst it would be 251 reasonable to forecast gradual increases in demand due to expected economic and population growth, the 252 data indicate that average flow rates decreased substantially during the 1990s. Given that turbines are 253 designed (and would be selected) according to a particular performance band, this reduction in flow rate 254 could impact turbine efficiency and thus energy recovery. During the 2000s, a general increasing trend 255 in demand was evident in line with the Irish economic boom period but a second prolonged decrease 256 was observed at the smallest PRV site, Merrion Gates. Such deviation creates difficulties when 257 attempting to optimise the turbine design flow. In contrast to flow rates, long-term variations in head 258 were less extreme across sites. Figures S1 to S2 in the supplementary materials sections illustrates the 259 variation in power output using the 3 turbine options considered here.

Figure 4. Long-term flow and head variation across three PRV sites. a) Thomas Court, 145 kW (1994 2013); b) Blackhorse Bridge, 75 kW (1996 - 2013) and c) Merrion Gates, 12.5 kW (1993 - 2013).

\subsection{Turbine Comparisons: Energy Recovery Potential and Investment Payback}

265 The impact of turbine selection on energy recovery and payback periods is presented in Table 2. 266 Estimated gross income was calculated assuming an annual power generation based on the design year 267 (i.e. performance was projected over the 20-year period based on a design flow from year 1 only, as 268 would be standard practice). Subsequently, actual gross income was determined, reflecting analysis of 
the true fluctuations in power generation over the subsequent 16-19 years for each site. For the two-PAT scenario, the percentage of time the smaller sized PAT was in use over the period is also shown.

Findings revealed that significant power generation capacity exists across each of the scenarios. The Kaplan produced the greatest amount of energy across all sites, owing to its higher overall efficiency compared to the PAT (as illustrated in Figure 3). However, the Kaplan cost approximately 25\% more to install than either a single PAT or two PATs system. This is in line with previous research which also highlighted the lower cost of PATs when compared to conventional turbines (Williams 1996; Nautiyal and Varun 2010). Furthermore, the cost difference was greater at the site with the lowest power output potential (the Kaplan turbine cost $29 \%$ more than a PAT).

Table 2. Estimates of total energy generated, capital cost, estimated and actual gross income, payback periods and smaller PAT viability for varying turbine scenarios across three PRV sites.

Acceptable payback periods were identified for those sites with medium and larger power capacities, although the actual payback period was generally higher than the estimated payback across these sites. The installation of a single PAT had the longest payback across all sites whilst the Kaplan was the best turbine choice regarding the shortest payback period. However, the difference in payback between the Kaplan and two PATs was only one year in total. In terms of the PRV with the smallest power potential (Merrion Gates), only the two-PAT scenario was found to have an economically viable payback period. Based on the design flow data (i.e. year 1 only), the initial payback estimates indicated that none of the turbine scenarios would achieve a viable payback period. However, the effects of considerable flow variation over the twenty years meant that the second smaller PAT was the best choice turbine $52 \%$ of the time. Figure 5 illustrates the two-PAT scenario in greater detail indicating the 
292 effects of long-term flow variation on turbine efficiency and viability. Evidently, this site exhibits high 293 flow variability and as the flow rate decreases, deviating from the turbine design flow of the larger PAT, 294 the second smaller PAT becomes the better choice in maximising efficiency and power output. 295 Interestingly, the smaller PAT was utilised less frequently across the larger PRV sites due to relatively 296 lower variation in flow conditions.

297 From an environmental output perspective, Table 3 highlights the total $\mathrm{CO}_{2}$ emission savings from 298 electricity generation for each turbine option. The Kaplan achieved the greatest savings potential across 299 all PRVs and almost double that of a single PAT at Thomas Court PRV, the site with the largest power 300 output capacity.

Figure 5. Long-term annual flow variation and performance of a two-PAT scenario at Merrion Gates PRV, displaying an annual breakdown of the percentage of time each PAT option was the near-optimal choice in achieving maximum turbine efficiency. PAT 1 represents the larger PAT developed for the design flow whilst PAT 2 is designed for $50 \%$ less than the design flow.

Table 3. Comparison of $\mathrm{CO}_{2}$ emissions savings estimates for varying turbine scenarios across three PRVs in Dublin.

\section{Discussion}

311 This research revealed the potential risks posed by long-term flow variation on energy recovery using 312 MHP installations into the future, thus highlighting the importance of this consideration when estimating 313 turbine suitability. The incorporation of high resolution flow and head data allowed for a more realistic 314 assessment of power potential over the long-term given the detailed diurnal, daily, seasonal and annual 315 fluctuations in flow rates which can influence turbine efficiency and viability into the future. 


\subsection{Long-term Flow Variation Across Sites}

318 The analysis of long-term flow and head data across a number of PRVs identified considerable 319 fluctuations in flow conditions across sites, within the same small geographical region. Thus, site 320 characteristics such as the district type e.g. commercial or residential, play a strong role in overall 321 demand requirements. It was anticipated that demand would increase in line with economic and 322 population growth but not all sites reflected this. The smallest PRV, Merrion Gates, experienced a 323 reduction in demand during the 2000s. Such variation in flow conditions indicates the complexity in 324 determining an optimum design flow for a turbine. Thus, anticipating the challenge of long-term flow is 325 vital when assessing the potential feasibility of varying turbine options. Accordingly, in order to achieve 326 maximum energy recovery and long-term viability of such installations, improved flexibility in turbine 327 operation is essential where flow and head are expected to deviate substantially.

5.2 Turbine Comparisons and the Role of PAT Technology in Accommodating Increased Flow Variability

331 In order to advance the uptake of MHP technology a viable installation must comprise a minimum 332 payback period, maximise power output and revenue generation and reduce $\mathrm{CO}_{2}$ emissions. 333 Furthermore, it must have the adaptive capacity to accommodate changing flow conditions over the 334 long-term. The impact of long-term flow and head variation on estimated energy recovery and 335 investment payback periods across three turbine scenarios revealed some valuable insights.

336 Firstly, the conventional Kaplan turbine was the best choice in terms of payback periods at the PRV 337 sites with greater power output potential, whilst a single PAT installation had the longest payback across 338 all sites. The superior performance of the Kaplan was due to its higher overall efficiency as shown in 
339 Figure 3. The Kaplan also maintained higher efficiency over a wider range of partial flows. However, 340 the payback period differed by only one year between the Kaplan and two-PAT scenario. In terms of 341 environmental benefit, the Kaplan produced the greatest reduction in $\mathrm{CO}_{2}$ emissions; between $37 \%$ and $34248 \%$ more than a single PAT and between $25 \%$ and $43 \%$ more than a two-PAT option when comparing 343 sites. Yet, a significant disadvantage with the Kaplan is that it costs $25 \%$ more to install when compared 344 to either a single PAT or two PATs in parallel and this cost differential increased even further when 345 assessing economic viability at the smallest PRV site. Furthermore, the miniaturisation of traditional 346 turbine types such as the Kaplan is known to be prohibitively expensive, rendering them unsuitable for 347 the large number of potential MHP energy recovery sites with small output capacities. the Merrion Gates PRV site which had the smallest energy recovery potential of $12.5 \mathrm{~kW}$ and the greatest flow variability. In contrast the single PAT displayed a significantly longer payback period of 35216 years whilst the Kaplan had a payback of 11 years and considerable upfront costs. The notably cost 353 effective option of a PAT when compared to a Kaplan, allows for the possibility of integrating more 354 than one PAT in parallel with small additional costs. This turbine solution of multiple PATs with 355 varying design flows in order to cater for flow variation can improve the overall energy generation 356 potential of PATs and the low installation cost coupled with comparable payback periods when 357 compared to conventional turbines highlights its economic advantages.

358 Thus, the integration of PAT technology within water supply networks potentially opens up the 359 opportunity to harness untapped recoverable energy at MHP sites with smaller power generation 360 potential and in locations where there exists large hydraulic variability, sites which may previously have 361 been considered unsuitable for MHP. Indeed it is worth emphasising the importance of this finding 362 where recent research has highlighted that the majority of MHP energy recovery opportunities in water 
networks in Ireland and the UK were located at PRVs (>67\%) and the majority of these sites had small power output capacities (2-20 kW) (Gallagher et al. 2015).

\subsection{Limitations and Areas for Further Research}

The simulation of hypothetical scenarios presented in the current study, where each turbine was designed based on one year of historical data and its performance was assessed across the subsequent 16 to 19 years, was useful to examine performance variability over time. However, in practice, hydropower turbine designers will not know the future flow rate or available head over the coming 20 year period, making the design of turbines which cater for future flow variations difficult. The use of water demand forecasting models have an important role to play here to enable the variation in flow at PRVs in water distribution networks to be predicted over the long-term. Corcoran et al. (2016), recently outlined the development of a model of water demand forecasting for MHP installations at PRV sites, where temperature, economic growth, population change, leakage and water pricing were significant influencing factors. This and/or other similar demand forecasting models are a required prerequisite to the design of the two PAT system described here.

Furthermore, the current approach presented a two-PAT scenario in which the smaller PAT was designed for $50 \%$ less than the design flow. In essence, a range of alternative design flows could be incorporated $(80 \%, 120 \%$, etc.). Optimisation research of various design flow options, in terms of the optimum number and size of PATs, would allow for improved decision making for utility managers regarding the most economically advantageous PAT configuration. Ideally where flow is split between two PATs to cater for flow variation, each PAT should be in operation closer to $50 \%$ of the time to achieve a useful benefit from the use of a second turbine. However, such an optimisation requires a prediction of future flow rates at a given site, which may be subject to large uncertainty. 
A further limitation of the current work lies in the estimation of MHP cost, and particularly PAT cost. PAT costs have been widely reported in literature as being 10-20 times less expensive than conventional turbines and figures in the range of $€ 115-€ 350 / \mathrm{kW}$ have also been published (Teuteberg 2010; Motwani et al. 2013; Caravetta et al. 2014b; Power et al. 2014). However a cost-head-power relationship such as that described in Equation 3 for the Kaplan would predict PAT costs with more confidence than the existing cost-power relationship. Further research is required to develop such a relationship for PATs. In addition, future preliminary designs of micro-hydropower energy recovery at PRVs, incorporating analysis of this nature would benefit from the incorporation of a sensitivity analysis. In the absence of the aforementioned PAT cost model, a sensitivity analysis testing the impact of uncertainties such as the cost of PATs, costs of Kaplans and cost of electricity, should be conducted.

Assuming that the electromechanical equipment comprise $30 \%$ of the total project cost is also subject to error. Gallagher et al. (2015) recently highlighted that in the water network setting this percentage of cost varied from $30 \%$ to $70 \%$ based on local flow conditions and the size of the installation. However, as the absolute cost of each site is not the valuable contribution of this paper, rather the relative impact of turbine choice at each site and across the sites, this assumption does not adversely impact on the findings.

402

\section{Conclusion}

404 Micro-hydropower represents a viable pathway to a more sustainable system of water supply, yet uptake 405 of this technology remains low and sporadic due to a range of risk factors which include long-term flow 406 and head variations potentially impacting on economic viability assessments. The focus of this study 407 was to undertake a detailed investigation of the impact of long-term flow variability on turbine operating 408 efficiencies and power output across a number of turbine design scenarios over a twenty year period 409 using Dublin as a case study site. Findings revealed that considerable variation in long-term flow 
conditions occurred over the 20 years, particularly at PRV sites with smaller power generation capacities, while head levels did not vary to the same degree.

Following investment payback analysis, the Kaplan was found to have the shortest payback period and achieved the largest saving in $\mathrm{CO}_{2}$ emissions across both medium and large MHP sites. However, neither the conventional turbine nor single PAT were found to be economically viable, at the most commonly occurring, smallest PRV site. Although there was an evident reduction in power generation, the two-PAT scenario proved to be economically viable despite the increased flow variability. Furthermore, this option was almost comparable with the Kaplan in terms of payback period across the remaining sites and had a significantly lower installation cost.

Therefore, the incorporation of multiple PATs in parallel represents a viable technology option which demonstrates resilience and flexibility to future fluctuations in flow and head conditions, enhancing the adaptive capacity of MHP systems into the long-term. Previous investigations examining the available resources for MHP energy recovery have highlighted that the majority of potential MHP sites lies in this small capacity range, similar to the Merrion Gates site examined here. Such sites would not have been previously considered economically viable due to the extent of flow variation and low power output.

The present study is of relevance for water utilities as it highlights an adaptive design option to maximise energy recovery potential within water distribution networks. Accordingly, the findings strengthen the evidence base for greater uptake of MHP technology and PATs.

\section{Acknowledgements}

This project is part funded by the European Regional Development Fund (ERDF) through the IrelandWales Programme (INTERREG 4A). The authors wish to extend a sincere thank you to Dublin City Council for the provision of data and information. 
References

436

437

438

439

440

441

442

443

444

445

446

447

448

449

450

451

452

453

454

455

456

Agarwal, T. (2012). Review of pump as turbine (PAT) for micro-hydropower. Int. J. Emerg. Tech. \& Adv. Eng., 2, 163-169.

Carravetta, A., Del Giudice, G., Fecarotta, O., and Ramos, H.M (2013). PAT design strategy for energy recovery in water disribution networks by electrical regulation. Energies., 6, 411-424.

Carravetta, A., Del Giudice, G., Fecarotta, O., and Ramos, H.M. (2012). Energy Production in Water Distribution Networks: A PAT Design Strategy. Water Resour. Manage., doi: 10.1007/s11269-0120114-1

Carravetta, A., Fecarotta, O., Del Giudice, G., and Ramos H.M. (2014a). Energy recovery in water systems by PATs: A comparisons among the different installation schemes. Proc. Eng., 70, 275284. doi: 10.1016/j.proeng.2014.02.031

Carravetta, A., Fecarotta, O., Sinagra, M., and Tucciarelli, T. (2014b). Cost Benefit Analysis for Hydropower Production in Water Distribution Networks by a Pump as Turbine. J. Water. Resour. Plann. Manage. doi: 10.1061/(ASCE)WR.1943-5452.0000384

Colombo, A., and Kleiner, Y. (2011). Energy recovery in water distribution systems using microturbines. Prob. Method. Water Waste. Eng. 23-27, 1-9.

Corcoran, L., Coughlan, P., and McNabola, A. (2013). Energy Recovery Potential using Micro Hydropower in Water Supply Networks in the UK \& Ireland. Water Sci. \& Tech. Water Sup. 13, $552-560$.

Corcoran, L., McNabola, A., and Coughlan, P. (2012). Energy recovery potential of the Dublin region water supply network. Proc., Int. Water Association: World Congress on Water, Climate and Energy. IWA Publishing, Dublin, Ireland. 
457 Corcoran, L., McNabola, A., and Coughlan, P. (2016). Predicting and quantifying the effect of variations

458 in long-term water demand on micro-hydropower energy recovery in water supply networks. Urb. $459 \quad$ Water. In Press

460 Daigger, G.T. (2009). Evolving urban water and residuals management paradigms: Water reclamation 461 and reuse, decentralization and resource recovery. Water Env. Res. 81, 809-823

462 DEFRA (2008). Future water- The Government's water strategy for England. Department for $463 \quad$ Environment, Food and Rural Affairs. Norwich

464 DoEHLG (2010). Report of the Local Government Efficiency Review Group. Department of the 465 Environment, Heritage and Local Government. Dublin 466 Environment Agency (2009). Renewable energy potential for the water industry. Bristol 467 ESHA (2004). Guide on How to Develop a Small Hydropower Plant. European Small Hydropower $468 \quad$ Association. Brussels

469 Eurostat (2014a). Hydropower. In: Energy Resources - Hydropower. http://epp.eurostat.ec.europa.eu/portal/page/portal/data_centre_natural_resources/natural_resources/ energy_resources/hydropower. Accessed 1 Dec 2015

472 Eurostat (2014b). Electricity and natural gas price statistics. In: Eurostat Statistics Explained http://epp.eurostatec.europa.eu/statisticsexplained/index.php/. Accessed 1 Dec 2015

Fecarotta, O., Aricò, C., Carravetta, A., Martino, R., and Ramos, H.M. (2015). Hydropower Potential in Water Distribution Networks: Pressure Control by PATs. Water Resourc. Manage. 29, 699-714. doi: $10.1007 / \mathrm{s} 11269-014-0836-3$

Gaius-obaseki T (2010). Hydropower opportunities in the water industry. International Journal of Environ. Sci. 1, 392-402.

Gallagher, J., Harris, I.M., Packwood, A.J, McNabola, A., and Williams, A.P. (2015). A strategic assessment of micro-hydropower energy recovery in the UK and Irish water industry: Identifying technical and economic constraints. Renew. Energy. doi: 10.1016/j.renene.2015.03.078 
García, J.P., Marco, A.C., and Santos, S.N. (2010). Use of centrifugal pumps operating as turbines for energy recovery in water distribution networks. Two case study. Adv. Materials Res. 107, 87-92.

Giugni, M., Fontana, N., and Ranucci, A. (2014). Optimal Location of PRVs and Turbines in Water Distribution Systems. J. Water Resourc. Plann. Manag. doi: 10.1061/(ASCE)WR.19435452.0000418 .

Koch, H., Vögele, S., Kaltofen, M., Grossmann, M., and Gunewald, U. (2014). Security of Water Supply and Electricity Production: Aspects of Integrated Management. Water Resourc. Manage. 28, 1767-1780. doi: 10.1007/s11269-014-0589-z

Kwok, S.C., Lang, H., and O'Callaghan, P. (2010). Water Technology Markets 2010: Key Opportunities and Emerging Trends. Oxford

McNabola, A., Coughlan, P., Corcoran, L., Power, C., Williams, A.P., Harris, I.M., Gallagher, J., and Styles, D. (2014a). Energy recovery in the water industry using micro-hydropower: An opportunity to improve sustainability. Water Pol. 16, 168-183.

McNabola, A., Coughlan, P. and Williams, A.P. (2014b). Energy recovery in the water industry: An assessment of the potential of micro-hydropower. Water Environ. J. 28, 294-304.

Motwani, K.H., Jain, S.V., and Patel, R.N. (2013). Cost Analysis of Pump as Turbine for Pico Hydropower Plants - A Case Study. Proc. Eng. 51, 721-726.

Nautiyal, H. and Varun, K.A. (2010). CFD analysis on pumps working as turbines. Hydro Nepal 6, 3537.

Ogayar, B., Vidal, P.G. and Hernandez, J.C. (2009). Analysis of the cost for the refurbishment of small hydropower plants. Renew. Energy, 34, 2501-2509. doi: 10.1016/j.renene.2009.03.027

Ørke, P.R. (2010). Zeropex: Pressure control with a payback. All Energy Exhibition and Conference 2010.

Paish, O. (2002). Small hydro power: Technology and current status. Renew. Sust. Energy Rev. 6, 537556. 
507 Power, C., Coughlan, P., and McNabola, A. (2014). Development of an evaluation method for

508 hydropower energy recovery in wastewater treatment plants: Case studies in Ireland and the UK. $509 \quad$ Sust. Energy Tech. Assess. 7, 166-177.

510 Ramos, H. and Borga, A. (1999). Pumps as turbines: An unconventional solution to energy production. 511 Urb. Water 1, 261-263. doi: 10.1016/S1462-0758(00)00016-9

512 Saket, R.K. (2008). Design, development and reliability evaluation of a micro hydro-power generation 513 system based on municipal waste water. Proc. IEE Electrical Power and Energy Conference. $514 \quad$ Vancouver, pp1-8

515 Samora, I., Hasmatuchi, V., Münch-Alligné, C., Franca, M.J., Schleiss, A.J., and Ramos, H.M. (2016). 516 Experimental characterization of a five blade tubular propeller turbine for pipe inline installation. 517 Renew. Energy. 95, 356-366.

518 SEAI, (2013). Energy in Ireland: Key Statistics 2013. Dublin

519 Sitzenfrei, R. and Rauch, W. (2015) Optimizing Small Hydropower Systems in Water Distribution 520 Systems Based on Long-Time-Series Simulation and Future Scenarios. J. Water Resourc. Plann. $521 \quad$ Manage doi: 10.1061/(ASCE)WR.1943-5452.0000537.

522 Sitzenfrei, R. and Von Leon, J. (2014). Long-time simulation of water distribution systems for the 523 design of small hydropower systems. Renew. Energy 72, doi: 10.1016/j.renene.2014.07.013 524 Sitzenfrei, R., Von Leon, J. and Rauch, W. (2014). Design and optimization of small hydropower 525 systems in water distribution networks based on 10-years simulation with Epanet2. Proc. Eng. 89, $526 \quad 533-539$.

527 Sweeney, J., Albanito, F., Brereton A, et al. (2008). Climate Change - Refining the Impacts for Ireland. $528 \quad$ EPA STRIVE Report. Wexford Ireland.

529 Teuteberg, B. (2010). Design of a Pump Microhydro System for an Abalone Farm. Stellenbosch $530 \quad$ University. 
531 UKWIR, (2010). Energy Efficiency in the Water Industry: A Compendium of Best Practices and Case

$532 \quad$ Studies - Global Report. London

533 Vicente, D.J., Garrote, L., Sánchez, R., and Santillán, D. (2016) Pressure Management in Water

534 Distribution Systems: Current Status, Proposals, and Future Trends. J. Water Resour. Plann.

$535 \quad$ Manage. 142(2): 04015061

536 Vilanova, M.R.N. and Balestieri, J.A.P. (2014). Hydropower recovery in water supply systems: Models

537 and case study. Energy Con. Manage. 84, 414-426. doi: 10.1016/j.enconman.2014.04.057

538 Williams, A.A., Smith, N., Bird, C. and Howard, M. (1998). Pumps as turbines and induction motors as

539 generators for energy recovery in water supply systems. J. Chart. Inst. Water Environ. Manage.

$540 \quad 12,175-178$.

541 Williams, A.A. (1996). Pumps as turbines for low cost micro hydro power. Proc. World Renew. Energy

$542 \quad$ Congress. 1227-1234

543 Zilberman, D., Sproul, T., Rajagopal, D., Sexton, S., and Hellegers, P. (2008). Rising energy prices and 544 the economics of water in agriculture. Water Pol. 10,11-21. 
Table 1. An overview of flow, head and power output estimates for three PRVs in Dublin. Power estimates were based on varying Kaplan turbine efficiencies, where the turbine design flow/pressure was assumed to be the average of the data from year 1 of the record.

\begin{tabular}{lccc}
\hline PRV Location & Flow $\left(\mathrm{m}^{3} / \mathrm{s}\right)$ & Head $(\mathrm{m})$ & Estimated Power Output $(\mathrm{kW})$ \\
\hline Thomas Court & 0.18 & 70.97 & 145.15 \\
Blackhorse & 0.24 & 43.9 & 75.44 \\
Bridge & & & \\
Merrion Gates & 0.32 & 7.84 & 12.5 \\
\end{tabular}


Table 2. Estimates of total energy generated, capital cost, estimated and actual gross income, payback periods and smaller PAT viability for varying turbine scenarios across three PRV sites.

\begin{tabular}{|c|c|c|c|c|c|c|c|c|}
\hline PRV Site & $\begin{array}{l}\text { Turbine } \\
\text { Scenario }\end{array}$ & $\begin{array}{c}\text { Capital } \\
\text { cost } \\
(€)\end{array}$ & $\begin{array}{c}\text { Estimated } \\
\text { gross } \\
\text { income } \\
(€ / y r)\end{array}$ & $\begin{array}{c}\text { Estimated } \\
\text { payback } \\
\text { (Years) }\end{array}$ & $\begin{array}{c}\text { Total } \\
\text { Generation } \\
(\mathrm{kWh} / \mathrm{yr})\end{array}$ & $\begin{array}{c}\text { Actual } \\
\text { gross } \\
\text { income } \\
(€ / \mathrm{yr})\end{array}$ & $\begin{array}{c}\text { Actual } \\
\text { payback } \\
\text { (Years) }\end{array}$ & $\begin{array}{l}\% \text { of time } \\
\text { smaller size } \\
\text { PAT in use }\end{array}$ \\
\hline Thomas & Kaplan & 509,080 & 153,656 & 3 & 943,520 & 127,766 & 4 & \\
\hline Court & PAT & 376,200 & 59,109 & 6 & 487,692 & 65,318 & 7 & \\
\hline$(145 \mathrm{~kW})$ & 2 PATs & 386,121 & 67,308 & 6 & 542,337 & 72,804 & 5 & 35 \\
\hline Blackhorse & Kaplan & 409,392 & 83,272 & 5 & 875,574 & 118,458 & 5 & \\
\hline Bridge & PAT & 306,921 & 63,830 & 5 & 554,964 & 74,534 & 6 & \\
\hline$(75 \mathrm{~kW})$ & 2 PATs & 317,095 & 66,927 & 5 & 586,298 & 80,323 & 6 & 26 \\
\hline Merrion & Kaplan & 235,375 & 12,621 & 19 & 185,440 & 23,909 & 11 & \\
\hline Gates & PAT & 168,129 & 9,387 & 18 & 103,879 & 12,735 & 16 & \\
\hline$(12.5 \mathrm{~kW})$ & 2 PATs & 169,813 & 10,164 & 17 & 139,003 & 17,547 & 10 & 52 \\
\hline
\end{tabular}


Table 3. Comparison of $\mathrm{CO}_{2}$ emissions savings estimates for varying turbine scenarios across three PRVs in Dublin.

\begin{tabular}{lcc}
\hline PRV Site & Turbine Scenario & $\begin{array}{c}\text { Total } \mathrm{CO}_{2} \text { emissions savings } \\
\text { (tonnes) }\end{array}$ \\
\hline Thomas Court & Kaplan & 8967 \\
$(145 \mathrm{~kW})$ & PAT & 4635 \\
& 2 PATs & 5154 \\
Blackhorse & Kaplan & 7396 \\
Bridge & & \\
$(75 \mathrm{~kW})$ & PAT & 4688 \\
& 2 PATs & 4953 \\
Merrion Gates & Kaplan & 1860 \\
$(12.5 \mathrm{~kW})$ & PAT & 1042 \\
& 2 PATs & 1394 \\
\hline
\end{tabular}




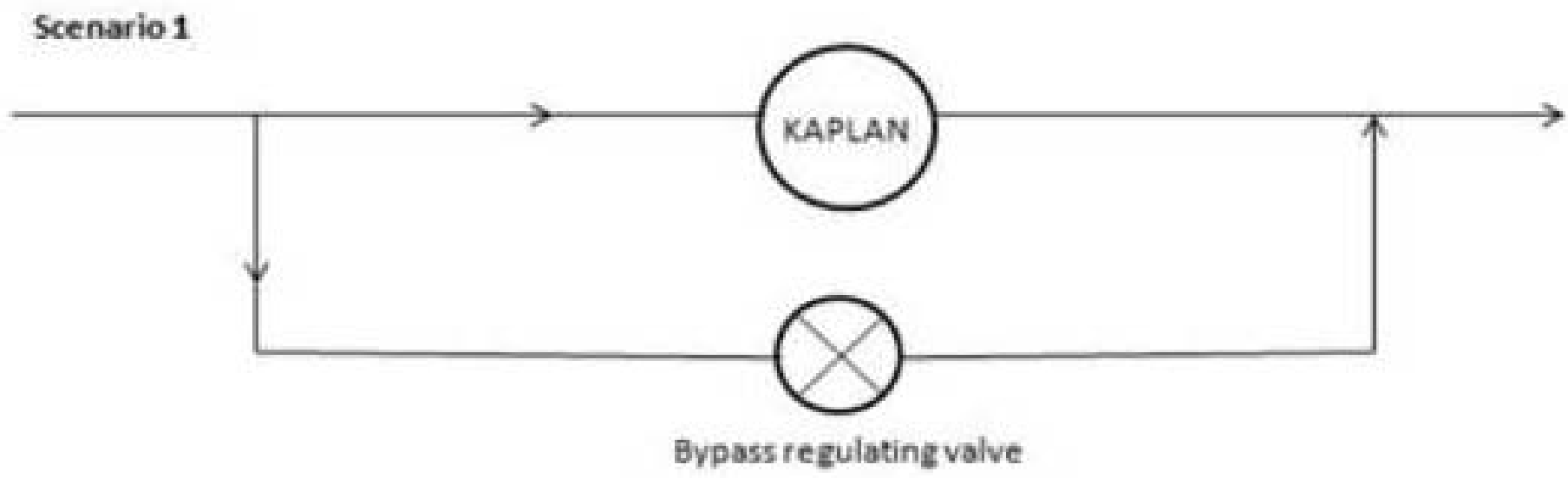

\section{Scenario 2}

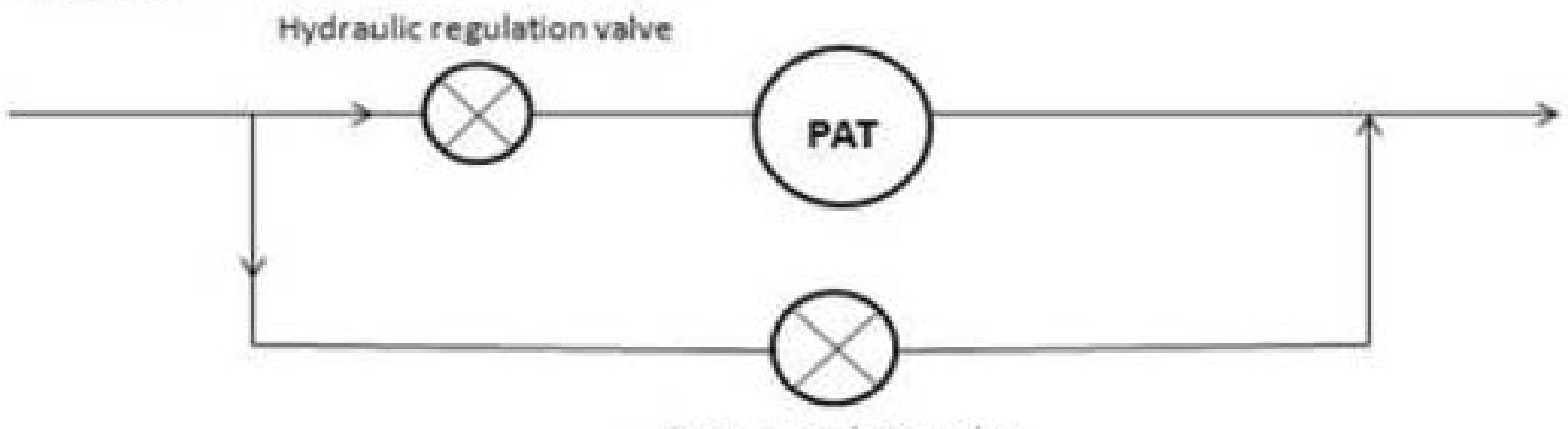

Bypass regulating valve

Scenario 3

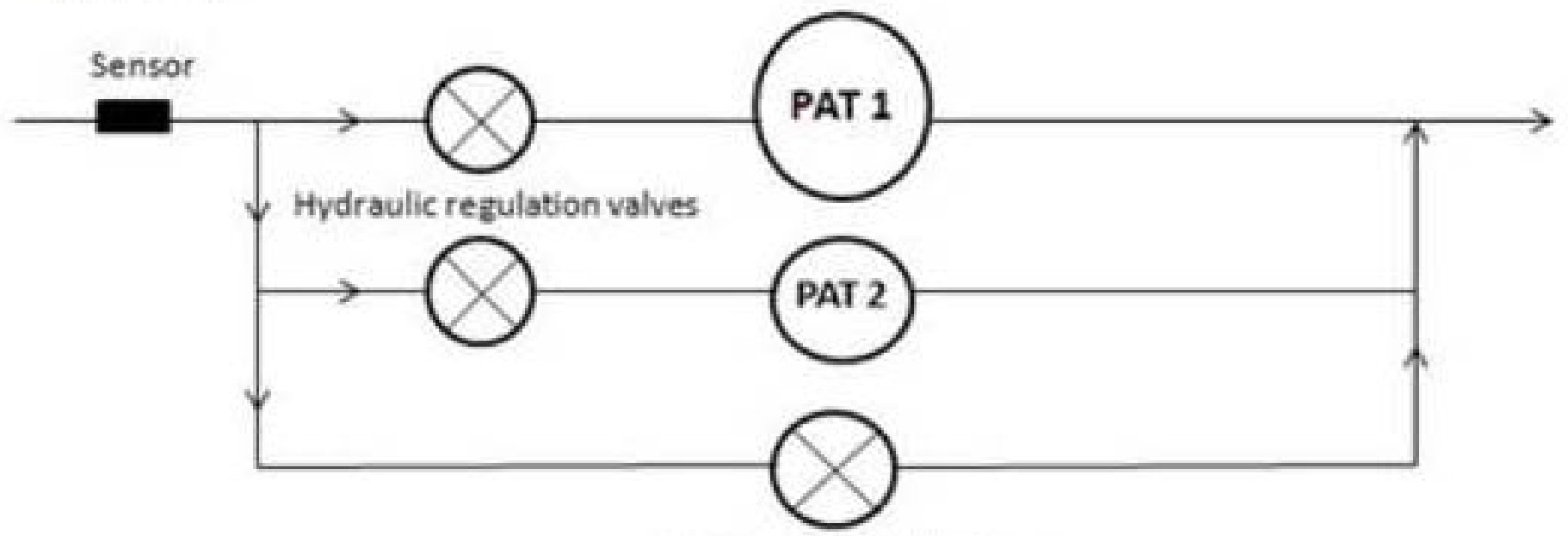

Bypass regulating valve 


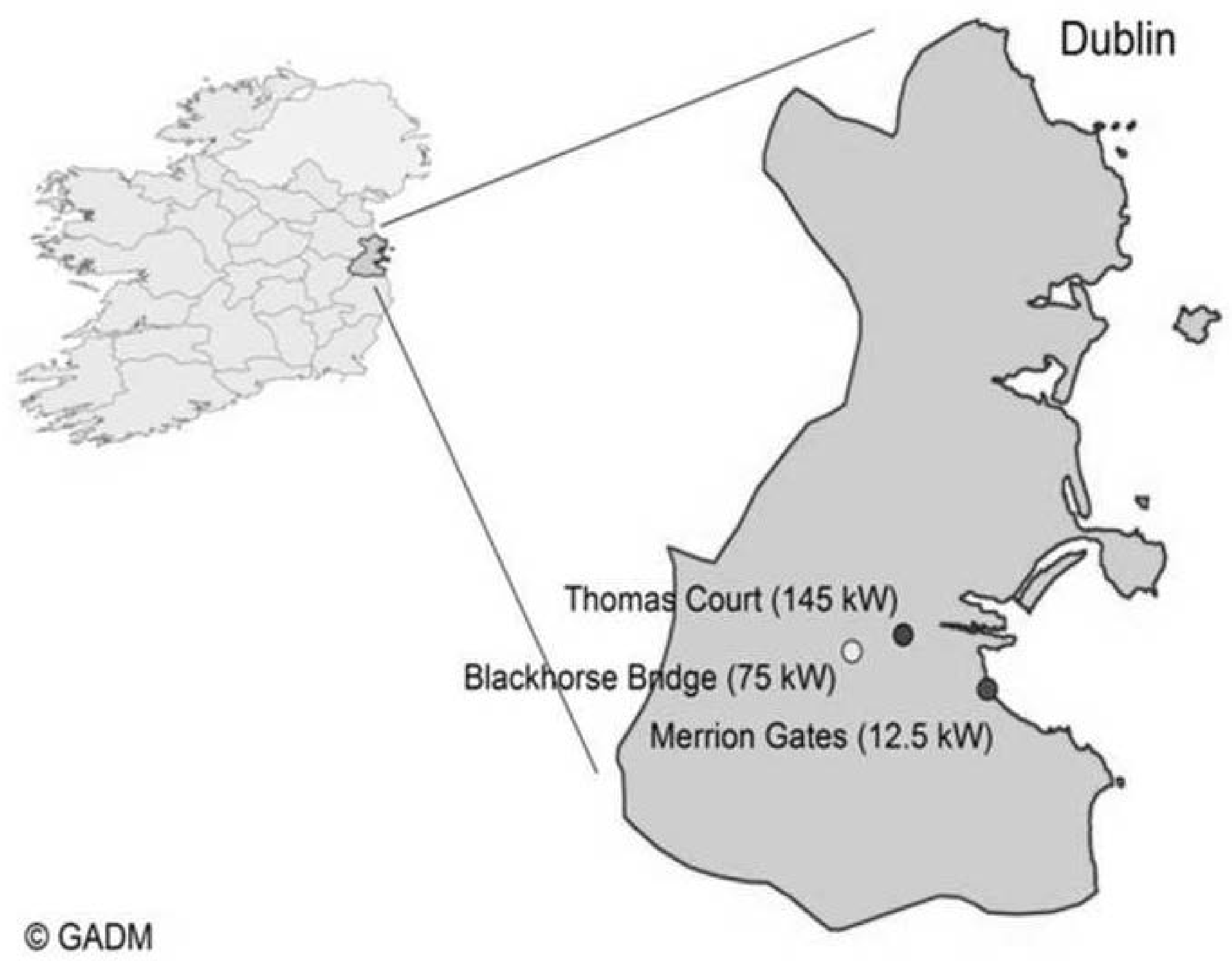




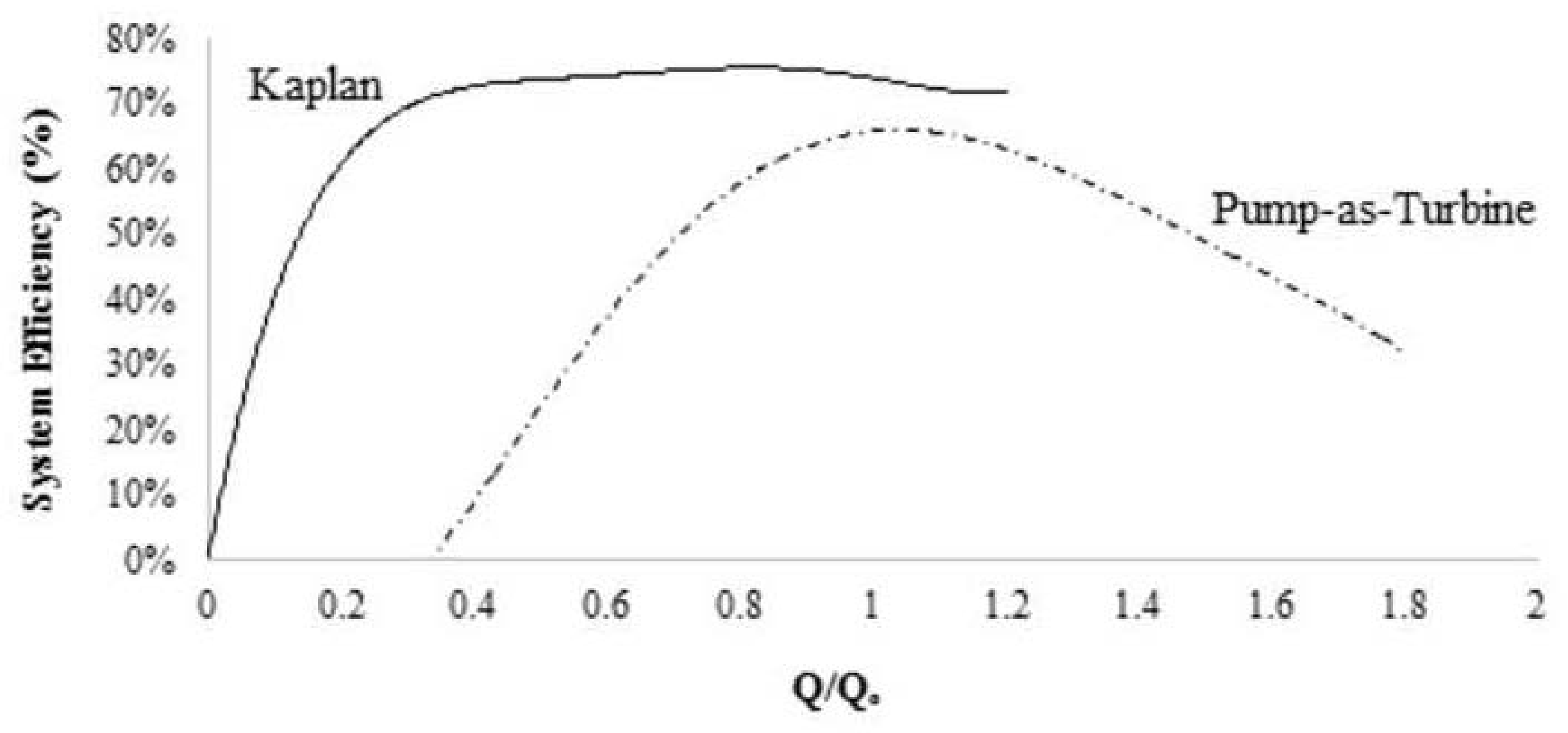



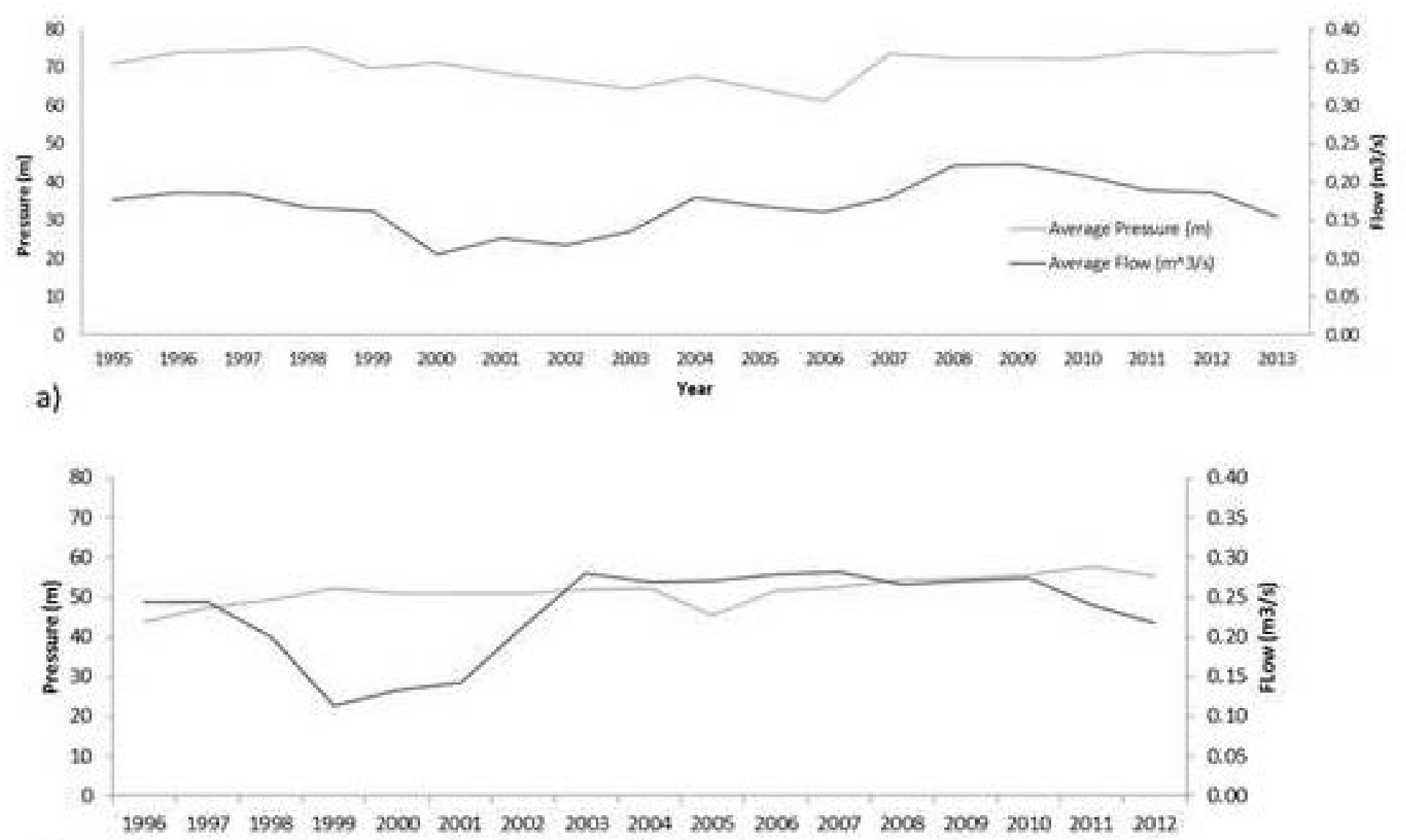

b)

Year

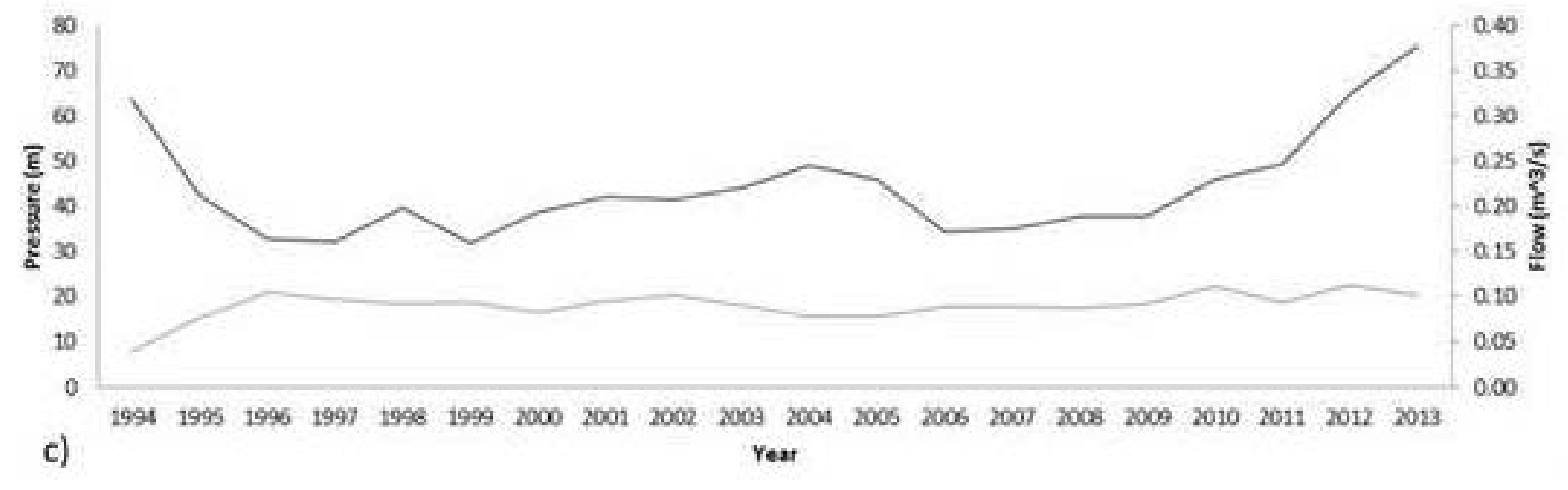




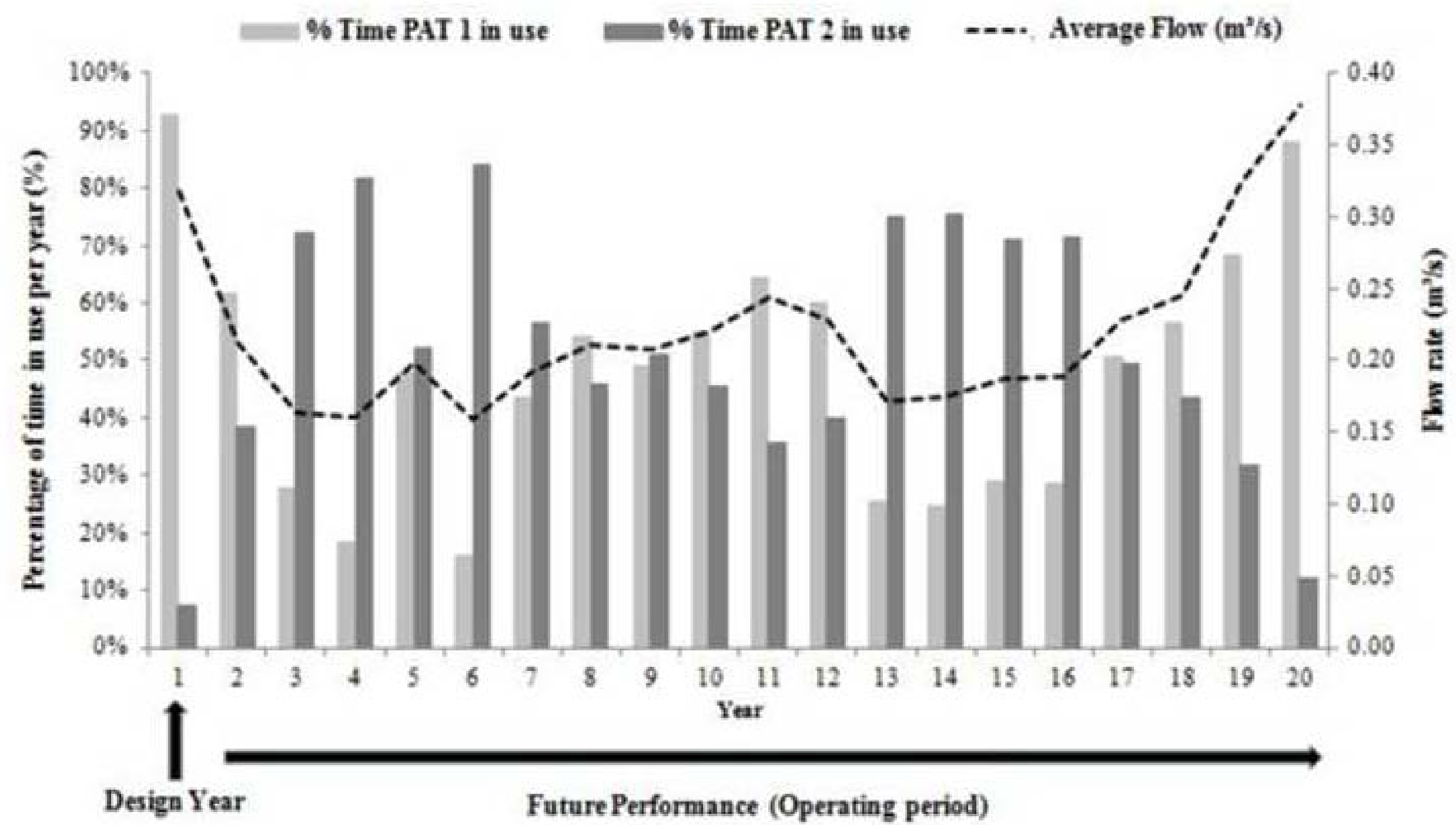


Figure 1. Installation schemes of three turbine scenarios; a Kaplan turbine, PAT and two PATs in parallel (Adapted from Carravetta et al. (2012)).

Figure 2. Map of the Dublin region displaying the location of the three pressure reducing valves used in the case study.

Figure 3. Overall system efficiency curves for the Kaplan turbine and PAT, assuming generator and transmission loss efficiencies of $85 \%$ and $98 \%$ respectively.

Figure 4. Long-term flow and pressure variation across three PRV sites. a) Thomas Court, $145 \mathrm{~kW}$ (1994 - 2013); b) Blackhorse Bridge, 75 kW (1996 - 2013) and c) Merrion Gates, 12.5 kW (1993 2013).

Figure 5. Long-term annual flow variation and performance of a two-PAT scenario at Merrion Gates PRV, displaying an annual breakdown of the percentage of time each PAT option was the nearoptimal choice in achieving maximum turbine efficiency. PAT 1 represents the larger PAT developed for the design flow whilst PAT 2 is designed for $50 \%$ less than the design flow. 
Click here to access/download Supplemental Data File

\section{Supplementary Data.docx}

